\title{
Peripheral eosinophilia - is it a predictable factor associated with eosinophilic cholecystitis?
}

\author{
Seung-Seop Yeom ${ }^{1}$, Ho-Hyun Kim${ }^{1}$, Jung-Chul Kim¹, Young-Hoe Hur ${ }^{1}$, Yang-Seok Koh', \\ Chol-Kyoon $\mathrm{Cho}^{1}$, Hyun-Jong Kim${ }^{1}$, Sang-Soo Shin ${ }^{2}$, and Hyung-Seok Kim ${ }^{3}$ \\ Departments of ${ }^{1}$ Surgery, ${ }^{2}$ Radiology, and ${ }^{3}$ Pathology, Chonnam National University \\ Medical School, Gwangju, Korea
}

\begin{abstract}
Backgrounds/Aims: The purpose of this study was to evaluate the role of peripheral eosinophilia as a predictable factor associated with Eosinophilic cholecystitis (EC) compared with other forms of cholecystitis in patients who underwent a cholecystectomy. Methods: Between January 2001 and May 2011, the histopathologic features of 3,539 cholecystectomy specimens were reviewed retrospectively. EC was diagnosed in 30 specimens (0.84\%). Data from 30 consecutive patients with EC (eosinophilic cholecystitis group [E-group]) were compared with a retrospective control group of 60 patients (other cholecystitis group [O-group]) during the same period. The two groups were matched for age, gender, and the presence of cholelithiasis. Results: The median absolute eosinophil count 1 day post-operatively was $144 \mathrm{cells} / \mathrm{mm}^{3}$ (range: $9-801$ cells $/ \mathrm{mm}^{3}$ ) in the E-group and $93 \mathrm{cells} / \mathrm{mm}^{3}$ (range: $0-490 \mathrm{cells} / \mathrm{mm}^{3}$ ) in the O-group $(p=0.036)$. Pre-operative peripheral eosinophilia was more common in the E-group than the O-group $(20 \%$ vs. $3.3 \%$, $p=0.015$ ). Multivariate analysis revealed that pre-operative peripheral eosinophilia was an independent significant predictable factor associated with EC (odds ratio=7.250, $1.365<95 \%$ confidence interval $<38.494, p=0.020$ ). Conclusions: In the present study, pre-operative peripheral eosinophilia was shown to be an independent predictable factor associated with EC. Further researches seem to be necessary to confirm this finding. (Korean J Hepatobiliary Pancreat Surg 2012;16:65-69)
\end{abstract}

Key Words: Eosinophilic cholecystitis; Eosinophilia; Predictable factor; Cholecystectomy

\section{INTRODUCTION}

Eosinophilic infiltration of the gallbladder based on histopathologic examination is a rare entity. Cellular infiltrates of the gallbladder comprising 90\% eosinophils are classified as eosinophilic cholecystitis (EC) (Fig. 1). ${ }^{1-3}$ The condition is termed lympho-eosinophilic cholecystitis when the infiltrate is comprised of $50-75 \%$ eosinophils along with other inflammatory cells in the gallbladder wall. $^{4-6}$ EC is a rare form of cholecystitis. ${ }^{7}$ Since EC was first described in 1949 by Albot et al, ${ }^{8}$ several case reports have been published in the English literature ( $<50$ cases). The condition likely represents a subgroup of patients with a unique or hypersensitive type of inflammatory response to altered bile. ${ }^{9}$

The etiology of EC is not completely understood, but might be associated with a hypersensitivity to antibiotics, other drugs, herbal medicines, hepatic echinococcosis, or as a variant manifestation of eosinophilic gastroenteritis. ${ }^{1,10}$ The diagnosis of EC is usually made based on histologic studies following cholecystectomy. The purpose of this study was to evaluate the role of peripheral eosinophilia as a predictable factor associated with EC compared with other types of cholecystitis in patients who underwent cholecystectomies.

\section{METHODS}

\section{Patients}

Between January 2001 and May 2011, 3539 patients underwent cholecystectomies for cholecystitis in the Department of Surgery, Chonnam National University Hospital. Thirty specimens $(0.84 \%)$ were confirmed pathologically to be EC. EC is defined as eosinophilic in-

Received: April 10, 2012; Revised: May 14, 2012; Accepted: May 16, 2012

Corresponding author: Jung-Chul Kim

Department of Surgery, Chonnam National University Medical School, 42, Jebong-ro, Dong-gu, Gwangju 501-757, Korea

Tel: +82-62-220-6456, Fax: +82-62-227-1635, E-mail: 3rdvivace@hanmail.net 

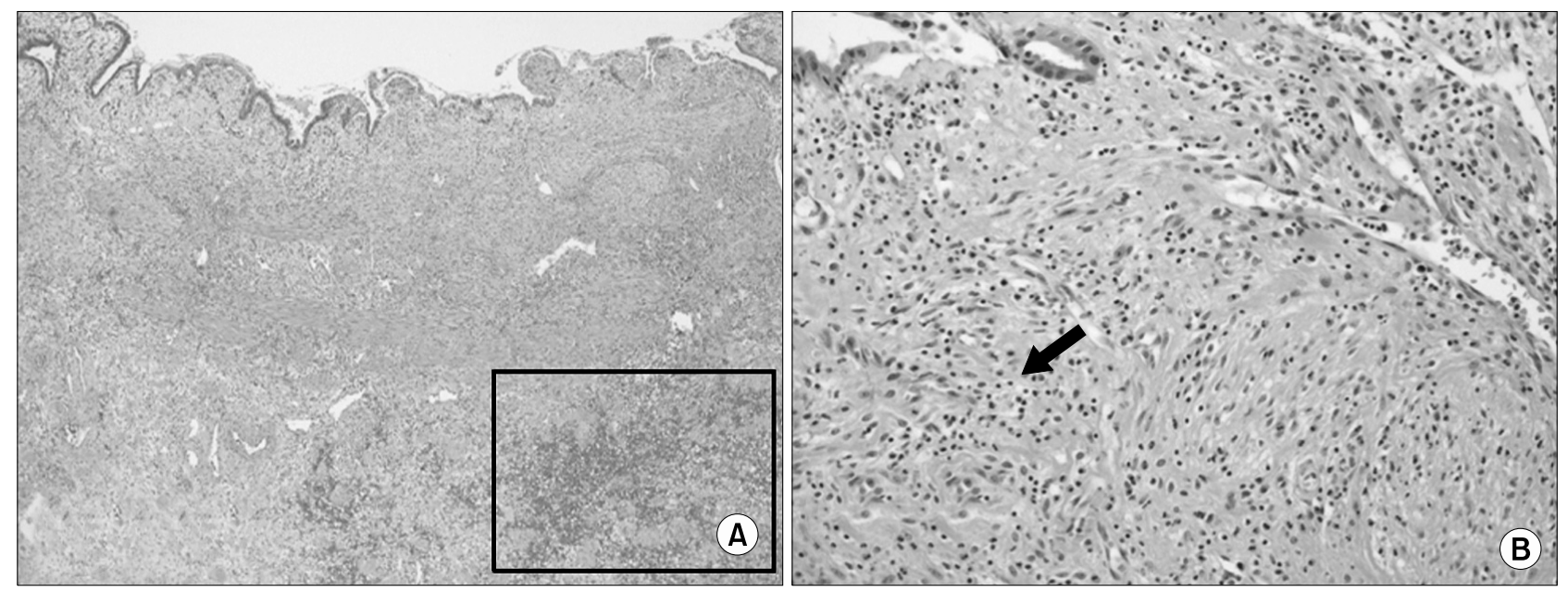

Fig. 1. Histopathology findings of eosinophilic cholecystitis. (A) Dense infiltration of eosinophils ([B] black arrow) involving the gallbladder diffusely in a transmural manner $(>90 \%$ ), suggesting eosinophilic cholecystitis (A: H\&E stain, $\times 40, \mathrm{~B}$ : H\&E stain, $\times 200)$.

filtration of the gallbladder wall consisting of $>90 \%$ eosinophils. $^{2}$

Data from 30 consecutive patients with EC (E-group) were compared with a retrospective control group of 60 patients (other cholecystitis group [O-group]) during the study period. The patients in the two groups were matched for age, gender, body mass index, the presence of cholelithiasis, jaundice, operative methods, and white blood cell count pre-operatively and 1 day post-operatively. The patients in the E- and O-groups had similar pre-operative assessments and post-operative management.

The clinical presentation (gender, age, and the presence of cholelithiasis), surgical methods, operative findings, histopathologic features, and pre- and post-operative absolute eosinophil count were analyzed retrospectively. Eosinophilia was defined as a condition in which the absolute eosinophil count in the peripheral blood exceeded $\geq 600$ cells $/ \mathrm{mm}^{3}$. 11

\section{Statistical analysis}

Summary statistics are reported using mean or median values, and standard deviation or range. The statistical evaluation was carried out using SPSS for Windows (version 17.0; SPSS, Inc., Chicago, IL, USA). A Student's $t$-test and Mann-Whitney U-test were used for the mean comparison of continuous variables and for ordinal data, respectively, whereas a chi-squared test and Fisher's exact test were used to compare frequencies of categorical vari- ables between the groups. To evaluate predictable factors for EC, a multivariate analysis was carried out by binary logistic multiple regression tests using dummy variable. Significance was defined as a $p \leq 0.05$.

\section{RESULTS}

The clinicopathologic features of patients are summarized in Table 1. Additional parameters, such as pre- and post-operative white blood cell count and operative method, were similar between the E- and O-groups.

\section{Clinical findings of patients with EC}

Table 1 lists the clinical features of the 30 patients with EC. The patients with EC were comprised of 21 males $(70.0 \%)$ and 9 females $(30.0 \%)$ with a median age of 63 years (range: 9-88 years). The mean body mass index (BMI) was $22.9 \pm 2.9 \mathrm{~kg} / \mathrm{m}^{2}$.

The clinical manifestations were not specific for EC. The main presenting complaint was abdominal pain $(82.8 \%)$ and epigastric discomfort (13.8\%). Two patients (6.7\%) were asymptomatic.

Cholecystolithiasis (gallbladder stones) and common bile duct stones were noted in $25(83.3 \%)$ and $6(20.0 \%)$ patients, respectively. Three patients $(10.0 \%)$ had obstructive jaundice based on the pre-operative laboratory examinations (Table 1), and 6 patients $(20.0 \%)$ had pre-operative peripheral eosinophilia (Table 2). 
Table 1. Clinical characteristics of patients with cholecystitis $(n=90)$

\begin{tabular}{|c|c|c|c|}
\hline Variable & E-group* $(n=30)$ & O-group ${ }^{\dagger}(n=60)$ & $p$-value \\
\hline Age (median, range) (years) & $63(9-88)$ & $64(11-88)$ & 0.857 \\
\hline Gender $(\%)$ & & & 0.635 \\
\hline Male & $21(70.0)$ & $39(65.0)$ & \\
\hline Female & $9(30.0)$ & $21(35.0)$ & \\
\hline $\mathrm{BMI}^{\ddagger}($ mean $\pm \mathrm{SD})\left(\mathrm{kg} / \mathrm{m}^{2}\right)$ & $22.9 \pm 2.9$ & $23.2 \pm 2.5$ & 0.693 \\
\hline GB stone $^{\S}(\%)$ & $25(83.3)$ & $50(83.3)$ & 1.000 \\
\hline CBD stone $\|(\%)$ & $6(20.0)$ & $12(20.0)$ & 1.000 \\
\hline Obstructive jaundice (\%) & $3(10.0)$ & $7(11.7)$ & 1.000 \\
\hline Operation method $(\%)$ & & & 0.821 \\
\hline Laparoscopic & $19(63.3)$ & $41(68.3)$ & \\
\hline Open & $8(26.7)$ & $15(25.0)$ & \\
\hline Open conversion & $3(10.0)$ & $4(6.7)$ & \\
\hline WBC_pre (median, range) (cells $\left./ \mathrm{mm}^{3}\right)$ & $7,100(3,600-26,100)$ & $6,450(2,900-21,300)$ & 0.204 \\
\hline WBC_post** (median, range) $\left(\right.$ cells $\left./ \mathrm{mm}^{3}\right)$ & $8,750(5,300-29,500)$ & $8,100(5,200-24,600)$ & 0.451 \\
\hline
\end{tabular}

*eosinophilic cholecystitis group, ${ }^{\dagger}$ other cholecystitis group, ${ }^{\dagger}$ body mass index, ${ }^{\S}$ gallbladder stone, " common bile duct stone, "white blood cell count on pre-operative laboratory findings, $* *$ white blood cell count on post-operative day 1

Table 2. Data comparison of the eosinophilic cholecystitis group and other cholecystitis group $(\mathrm{n}=90)$

\begin{tabular}{|c|c|c|c|}
\hline Variable & E-group* $(n=30)$ & O-group $^{\dagger}(n=60)$ & $p$-value \\
\hline Eosinophilia_pre $^{\ddagger}(\%)$ & $6(20.0)$ & $2(3.3)$ & 0.015 \\
\hline Eos_pre ${ }^{\prime}$ (median, range) $\left(\right.$ cells $\left./ \mathrm{mm}^{3}\right)$ & $209(0-1,559)$ & $147(0-621)$ & 0.174 \\
\hline Eosinophilia_post ${ }^{\S}(\%)$ & $2(6.7)$ & 0 & 0.109 \\
\hline Eos_post ${ }^{\Uparrow}$ (median, range) $\left(\right.$ cells $\left./ \mathrm{mm}^{3}\right)$ & $144(9-801)$ & $93(0-490)$ & 0.036 \\
\hline Eos_diff** (median, range) (cells $\left./ \mathrm{mm}^{3}\right)$ & $72(1-1,134)$ & $65(1-402)$ & 0.349 \\
\hline
\end{tabular}

*eosinophilic cholecystitis group, ${ }^{\dagger}$ other cholecystitis group, ${ }^{\dagger}$ pre-operative eosinophilia, ${ }^{\S}$ post-operative eosinophilia, $"$ absolute eosinophil count at pre-operative laboratory findings, absolute eosinophil count at post-operative day 1 , **difference in absolute eosinophil count between pre-operative and post-operative day 1

Table 3. Features of cases of eosinophilic cholecystitis with allergy or parasite infestation

\begin{tabular}{|c|c|c|c|c|c|c|}
\hline Case & Age (yr) & Sex & Allergy & Parasite & $\begin{array}{l}\text { Peripheral } \\
\text { eosinophilia }\end{array}$ & Gallstone \\
\hline 1 & 61 & Male & No & Yes (Clonorchis sinensis) & Yes & No \\
\hline 2 & 34 & Female & Yes (penicillin) & No & No & Yes \\
\hline
\end{tabular}

Only one of the 30 patients had a positive history for allergies (penicillin). This one case was due to a parasitic infestation (Clonorchis sinensis). None of the 30 cases were associated with drug therapy, or other pre-existing medical conditions (Table 3).

\section{Comparision of data between the EC and control groups (Table 2)}

The median pre-operative absolute eosinophil count was 209 cells $/ \mathrm{mm}^{3}$ (range: 0-1,553 cells $/ \mathrm{mm}^{3}$ ) in the E-group and 147 cells $/ \mathrm{mm}^{3}$ (range: 0-621 cells $/ \mathrm{mm}^{3}$ ) in the O-group. The median absolute eosinophil count on post-operative day 1 was 144 cells $/ \mathrm{mm}^{3}$ (range: 9-801 cells $/ \mathrm{mm}^{3}$ ) in E-group and 93 cells $/ \mathrm{mm}^{3}$ (range: 0-490) in O-group.

In the O-group, only 2 patients (3.3\%) had peripheral eosinophilia based on the pre-operative laboratory examinations. On the first post-operative day, no patient $(0 \%)$ demonstrated peripheral eosinophilia as compared to 2 patients $(6.7 \%)$ in the E-group.

The median absolute eosinophil count between pre-operative and post-operative day 1 was 72 cells $/ \mathrm{mm}^{3}$ in the E-group and 65 cells $/ \mathrm{mm}^{3}$ in the O-group. 
Table 4. Multivariate analysis for predictable factors associated with eosinophilic cholecystitis

\begin{tabular}{cclc}
\hline Variable & Odds ratio & \multicolumn{1}{c}{$95 \% \mathrm{CI}^{*}$} & $p$-value \\
\hline Eosinophilia_pre $^{\dagger}$ & 7.250 & $1.365-38.494$ & 0.020 \\
Eos_post $^{\dagger}$ & 1.002 & $0.997-1.006$ & 0.505 \\
\hline
\end{tabular}

*95\% confidence interval, ${ }^{\dagger}$ pre-operative eosinophilia, ${ }^{\dagger}$ absolute eosinophil count at post-operative day 1

\section{Univariate and multivariate analyses for pred-} ictable factors associated with EC (Table 2)

Univariate analysis revealed that pre-operative peripheral eosinophilia $(p=0.015)$ and the absolute eosinophil count on post-operative day $1(p=0.036)$ were significant predictable factors associated with EC (Table 2).

Multivariate analysis revealed that pre-operative peripheral eosinophilia was an independent predictable factor for EC (odds ratio $[\mathrm{OR}]=7.250,1.365<95 \%$ confidence interval $[\mathrm{CI}]<38.494$; $p=0.020$ ) (Table 4 ).

\section{DISCUSSION}

EC is an uncommon form of cholecystitis with an incidence ranging from $0.5-6.5 \%$ in cholecystectomy specimens $(2,7,12)$. The incidence of EC was $0.5 \%$ in a large review of 625 operative cholecystectomy specimens by Fox (2), and $6.4 \%$ in a review of 217 specimens by Dabbs. $^{12}$ In the present study, EC was diagnosed in 30 of 3539 specimens $(0.84 \%)$, which is comparable to the results of other reported series.

The etiology of EC is obscure, but the suggested origins include allergies, local diathesis involving gallstones, parasites, acalculous cholecystitis, hypereosinophilic syndrome (HES; in which eosinophils invade tissues, such as the brain, heart, lung, liver, and gallbladder), and eosinophilic gastroenteritis. ${ }^{1,3,12-17}$ It has been reported that EC might be associated with hypersensitivity to antibiotics, other drugs, and herbal medicines. ${ }^{1,10}$

A literature review showed that most patients with EC had an idiopathic etiology. ${ }^{1,18}$ In the present study, only one of the 30 patients had a positive history for allergies (penicillin). This case was due to a parasitic infestation, Clonorchis sinensis. Most patients (26 of 30 patients) had idiopathic EC. None of the 30 patients had an association with drug therapy or other pre-existing medical conditions. Therefore, the etiology of EC was not a predictable factor associated with the population for this study.

In addition, EC has a clinical presentation similar to typical cholecystitis with right upper quadrant pain and an elicited Murphy's sign. In clinical practice, EC is clinically indistinguishable from the most common form of acute cholecystitis $(2,13)$. Therefore, there is no known specific predictable factor for EC and the diagnosis of EC is based on the histopathology of cholecystectomy specimens. The characteristic histologic features of EC is transmural inflammatory infiltration of the gallbladder wall that is comprised of $>90 \%$ eosinophils. ${ }^{1,3}$ Eosinophils are one of the immune system white blood cells components responsible for combating multicellular parasites and infections in vertebrates. Along with mast cells, eosinophils also control the mechanisms associated with allergy and asthma. An increase in eosinophils typically occurs in people with parasite infestation of the intestines, collagen vascular disease (rheumatoid arthritis), malignant disease (Hodgkin's disease), extensive skin disease (exfoliative dermatitis), Addison's disease, and the use of certain drugs (penicillin). ${ }^{11}$

It has been reported that a laboratory examination sometimes reveals peripheral blood eosinophilia in patients with EC. ${ }^{3,10,15,16,19-21} \mathrm{Kim}^{1}$ reported that peripheral eosinophilia occurred in 4 of 15 cases. In contrast, it has been reported that EC has peripheral eosinophilia or specific laboratory features. $^{13,22}$

In the present study, pre-operative peripheral eosinophilia ( $\geq 600$ cells $/ \mathrm{mm}^{3}$ ) was noted in 6 of the 30 cases $(20 \%)$ in the E-group. There was a statistically significant difference between the E-group and the O-group ( $\mathrm{OR}=$ 7.250, $1.365<95 \%$ CI <38.494; $p=0.020$ ). Therefore, if patients with cholecystitis have pre-operative peripheral eosinophilia, there is great potential that the subtype of cholecystitis is EC. The pathogenesis and etiology of EC are not well-understood, but the presence of peripheral eosinophilia and abundant eosinophils in the gallbladder wall provide some support that the disease is mediated by a hypersensitivity-type reaction. Although the mechanism for gallbladder recruitment of eosinophils in EC is unknown, Desreumaux et al. $^{23}$ reported that eosinophil recruitment and activation is induced by cytokines, such as interleukin (IL)-3, granulocyte-macrophage colony-stimulating factor (GM-CSF), and IL-5, in eosinophilic gastroenteris. Therefore, we suggest that further evalua- 
tion is necessary for the molecular mechanism predisposing to peripheral eosinophilia and eosinophilic infiltration in patients with EC.

Nevertheless, the results of our study were limited by the non-randomized design, a small number of cases, and the selection bias related to the choice of approach based merely on demographic characteristics. And whether the result of our study is clinically relevant or not remains debatable. Thus, a larger group of patients is necessary to analyze the predictable factors associated with EC.

In summary, EC is a rare entity that is generally found only in cholecystectomy specimens. The etiology is obscure, but involves local and systemic eosinophilic inflammatory reactions. The diagnosis of the EC is usually made based on histologic studies following cholecystectomy. In the present study, pre-operative peripheral eosinophilia $\left(\geq 600\right.$ cells $/ \mathrm{mm}^{3}$ ) was found to be a significant predictable factor for EC. Further researches seem to be necessary to confirm this finding.

\section{REFERENCES}

1. Kim YH. Eosinophilic cholecystitis in association with clonorchis sinensis infestation in the common bile duct. Clin Radiol 1999;54:552-554.

2. Fox H, Mainwaring AR. Eosinophilic infiltration of the gallbladder. Gastroenterology 1972;63:1049-1052.

3. Felman RH, Sutherland DB, Conklin JL, et al. Eosinophilic cholecystitis, appendiceal inflammation, pericarditis, and cephalosporin-associated eosinophilia. Dig Dis Sci 1994;39:418-422.

4. Sánchez-Pobre P, López-Ríos Moreno F, Colina F, et al. Eosinophilic cholecystitis: an infrequent cause of cholecystectomy. Gastroenterol Hepatol 1997;20:21-23.

5. Punia RP, Arya S, Jain P, et al. Eosinophilic and lympho-eosinophilic cholecystitis. Indian J Gastroenterol 2003;22:153-154.

6. Hellstrom HR. Eosinophilic and lymphoeosinophilic cholecystitis. Am J Surg Pathol 1994;18:215-216.

7. Kaji K, Yoshiji H, Yoshikawa M, et al. Eosinophilic cholecystitis along with pericarditis caused by Ascaris lumbricoides: a case report. World J Gastroenterol 2007;13:3760-3762.

8. Albot G, Poilleux, Olivier C, et al. Les cholecystites a eosinophils. Presse Med 1949;39:558-559.

9. Malik KA. Eosinophilic cholecystitis: an infrequent cause of cholecystectomy. Pakistan J Med Sci 2010;26:724-725.

10. Adusumilli PS, Lee B, Parekh K, et al. Acalculous eosinophilic cholecystitis from herbal medicine: a review of adverse effects of herbal medicine in surgical patients. Surgery 2002;131:352356.

11. Tefferi A. Blood eosinophilia: a new paradigm in disease classification, diagnosis, and treatment. Mayo Clin Proc 2005;80: 75-83.

12. Dabbs DJ. Eosinophilic and lymphoeosinophilic cholecystitis. Am J Surg Pathol 1993;17:497-501.

13. Rosengart TK, Rotterdam H, Ranson JH. Eosinophilic cholangitis: a self-limited cause of extrahepatic biliary obstruction. Am J Gastroenterol 1990;85:582-585.

14. Russell CO, Dowling JP, Marshall RD. Acute eosinophilic cholecystitis in association with hepatic echinococcosis. Gastroenterology 1979;77:758-760.

15. Tenner S, Roston A, Lichtenstein D, et al. Eosinophilic cholangiopathy. Gastrointest Endosc 1997;45:307-309.

16. al-Abdulla NA, Schulick RD, Regan F. Hypereosinophilic sclerosing cholangitis: findings using half-Fourier magnetic resonance imaging. Hepatogastroenterology 2000;47:359-361.

17. Hepburn A, Coady A, Livingstone J, et al. Eosinophilic cholecystitis as a possible late manifestation of the eosinophilia-myalgia syndrome. Clin Rheumatol 2000;19:470-472.

18. Shakov R, Simoni G, Villacin A, et al. Eosinophilic cholecystitis, with a review of the literature. Ann Clin Lab Sci 2007;37:182185.

19. Tajima K, Katagiri T. Deposits of eosinophil granule proteins in eosinophilic cholecystitis and eosinophilic colitis associated with hypereosinophilic syndrome. Dig Dis Sci 1996;41:282-288.

20. Butler TW, Feintuch TA, Caine WP Jr. Eosinophilic cholangitis, lymphadenopathy, and peripheral eosinophilia: a case report. Am J Gastroenterol 1985;80:572-574.

21. Muhlberger F. Morphology of eosinophilic cholecystitis and the problem of its allergic genesis. Int Arch Allergy Appl Immunol 1954;5:434-448.

22. Parry SW, Pelias ME, Browder W. Acalculous hypersensitivity cholecystitis: hypothesis of a new clinicopathologic entity. Surgery 1988;104:911-916.

23. Desreumaux P, Bloget F, Seguy D, et al. Interleukin 3, granulocyte-macrophage colony-stimulating factor, and interleukin 5 in eosinophilic gastroenteritis. Gastroenterology 1996;110:768774 . 